\title{
Attenuation of oxygen fluctuation-induced endoplasmic reticulum stress in human lens epithelial cells
}

\author{
XIAO-YU ZHENG ${ }^{1}$, JIA XU $^{2}, \mathrm{XI} \mathrm{CHEN}^{3}, \mathrm{WEI} \mathrm{LI}^{3}$ and TING-YAN WANG ${ }^{1}$ \\ ${ }^{1}$ Department of Ophthalmology, The Children's Hospital of Zhejiang University School of Medicine; \\ ${ }^{2}$ Department of Ophthalmology, The Second Affiliated Hospital of Zhejiang University School of Medicine; \\ ${ }^{3}$ The Central Laboratory, The Children's Hospital of Zhejiang University School of Medicine, \\ Hangzhou, Zhejiang 310003, P.R. China
}

Received August 21, 2014; Accepted May 28, 2015

DOI: $10.3892 / \mathrm{etm} .2015 .2725$

\begin{abstract}
Cataractogenic stresses are associated with the induction of endoplasmic reticulum (ER) stress. However, little is known about oxygen $\left(\mathrm{O}_{2}\right)$-induced ER stress in the lens. Cataract research has focused on elevated levels of $\mathrm{O}_{2}$ in lens epithelial cells (LECs). Excessive levels or a lack of $\mathrm{O}_{2}$ are known to induce ER stress whereas chronic ER stress activates the unfolded protein response (UPR). The present study investigated the hypothesis that the fluctuation of $\mathrm{O}_{2}$ levels induces a UPR, and may be controlled by maintaining human LECs (hLECs) in a specific concentration of $\mathrm{O}_{2}$. Human LECs were cultured in different atmospheric levels of $\mathrm{O}_{2}$. Hypoxic conditions were determined by the level of hypoxia-inducible factor (HIF)-1 $\alpha .2^{\prime}, 7^{\prime}$-Dichlorodihydrofluorescein diacetate and ethidium homodimer-1 staining were conducted to detect reactive oxygen species (ROS) and cell death, respectively. Protein blot analyses were performed with antibodies specific to antioxidant and UPR-specific proteins. Reverse transcription-quantitatative polymerase chain reaction assays were performed to quantify the mRNA levels of activated NF-E2-related factor 2 (Nrf2) and kelch-like ECH-associated protein 1 (Keap1). The treatment of human LECs with 0 and $20 \%$ atmospheric $\mathrm{O}_{2}$ activated $\mathrm{Nrf} 2 / \mathrm{Keap} 1$. The LECs shifted to $1 \%$ atmospheric $\mathrm{O}_{2}$ from 0,4 or $20 \%$ for $24 \mathrm{~h}$ showed decreased levels of Keap1. By contrast, hLECs cultured in $1 \%$ atmospheric $\mathrm{O}_{2}$ for $24 \mathrm{~h}$ and then shifted to 0,4 or $20 \%$ $\mathrm{O}_{2}$ exhibited a significant upregulation of Nrf2. These results suggest that oxidative stress proteins were not expressed in a $1 \% \mathrm{O}_{2}$ environment. The $\mathrm{O}_{2}$ levels in the culture medium were equilibrated within $2 \mathrm{~h}$ in the cell culture plates. These results
\end{abstract}

Correspondence to: Dr Xiao-Yu Zheng, Department of Ophthalmology, The Children's Hospital of Zhejiang University School of Medicine, 57 Zhugan Road, Hangzhou, Zhejiang 310003, P.R. China

E-mail: rainzheng7@126.com

Key words: unfolded protein response, low oxygen, hypoxia inducible factor- $1 \alpha$, antioxidants, NF-E2-related factor 2 showed that an appropriate oxygen environment for the culture of LECs is $\sim 1 \%$ atmospheric $\mathrm{O}_{2}$. Either 0 or $20 \%$ of atmospheric $\mathrm{O}_{2}$ activated the UPR and the Nrf2/Keap1-mediated antioxidant system in LECs and chronic exposure to $\mathrm{O}_{2}$ fluctuation led to ROS production and cell death. This study revealed that $\mathrm{O}_{2}$ fluctuation-induced UPR/ER stress could be prevented by maintaining the cells in a $1 \% \mathrm{O}_{2}$ environment.

\section{Introduction}

Cataract, the foremost cause of visual impairment, is found notably in diabetic patients and causes health and economic problems predominantly in developing countries (1). Genetic and environmental stresses combined with age are considered as leading contributors to aggregation, crystalline modification and pathogenesis in lens oxidation. The ciliary body and blood vessels of the iris supply glucose and oxygen $\left(\mathrm{O}_{2}\right)$ to the lens, where it is present in a hypoxic environment containing $0.5-2.3 \% \mathrm{O}_{2}(2-4)$. The level of $\mathrm{O}_{2}$ is a very important factor in cataract, and various cataractogenic stressors such as hypoxia, hypoxic conditions along with a low glucose level (5) or high glucose level (6), homocysteine (7), and galactose (6) are found to induce stress in the endoplasmic reticulum (ER), thereby mediating the activation of the unfolded protein response (UPR) along with the production of reactive oxygen species (ROS), which is usually abnormally increased, and lens epithelial cell (LEC) death $(3,8,9)$.

Osmotic stress, primarily caused by the accumulation of sugars, has been found to induce stress in the ER, which is a major site of protein synthesis, thereby leading to free radical generation. The stress is also found to result from fluctuations in glucose levels initiating an UPR that further generates ROS, and thus causes oxidative stress damage to lens fibers (10).

ER-induced UPR is reported to be activated by the phosphorylation of inositol-requiring enzyme-1 (IRE-1), PKR-like endoplasmic reticulum kinase (PERK) and eukaryotic translation initiation factor $2 \alpha(\mathrm{eIF} 2 \alpha)$ and this mechanism is also reported to be protective, although the cellular components are a stress response, whereas in prolonged UPR, apoptosis is induced by caspases (caspase-12) (11) and C/EBP homologous protein (CHOP) (12), death factors that are activated by activating transcription factor 4 (ATF4), which is a signifi- 
cant controller of mammalian lens development (13). Free radicals such as ROS are generated by the UPR in increased intensities (14) and in response, the upregulation of NF-E2related factor 2 (Nrf2) and activation of the PERK-dependent antioxidant defense system occurs due to the UPR (15).

This study aimed to determine whether hypoxic conditions or $\mathrm{O}_{2}$ fluctuation in the environment of LECs induces UPR, leading to ROS production and failure of the Nrf2dependent antioxidant defense protection. To elucidate this, UPR was studied along with the production of free radicals and the levels of Nrf2 in human LECs (hLECs) that were treated with various $\mathrm{O}_{2}$ environments.

\section{Materials and methods}

hLEC culture. hLECs (Lonza Clonetics ${ }^{\mathrm{TM}}$, Basel, Switzerland) were cultured overnight in Dulbecco's modified Eagle's medium (DMEM; Invitrogen Life Technologies, Carlsbad, CA, USA) containing $25 \mathrm{mM}$ glucose, along with $10 \%$ fetal calf serum (FCS) under $20 \%$ atmospheric $\mathrm{O}_{2}$ at $37^{\circ} \mathrm{C}$. Prior to each experiment, the hLECs were precultured overnight in DMEM with $5 \mathrm{mM}$ glucose and $4 \%$ atmospheric $\mathrm{O}_{2}$. The hLECs were then cultured under various conditions. Some were cultured in glucose-free (GF) DMEM supplemented with $2 \% \mathrm{FCS}$ and were maintained at $37^{\circ} \mathrm{C}$ in $20 \%$ atmospheric $\mathrm{O}_{2}$. Some hLECs were maintained under anaerobic conditions $\left(0 \%\right.$ atmospheric $\left.\mathrm{O}_{2}\right)$ in an AnaeroGen vacuum bag (Sigma-Aldrich, St. Louis, MO, USA). Atmospheric $\mathrm{O}_{2}$ environments of 1 and $4 \%$ were maintained in an $\mathrm{O}_{2} / \mathrm{CO}_{2}$ incubator (SANYO MCO-19M CO $\mathrm{M}_{2}$ incubator; Sanyo, Tokyo, Japan) attached to a liquid nitrogen gas tank. A normal tissue culture incubator (SANYO MCO-19M CO $\mathrm{M}_{2}$ incubator; Sanyo) was used to maintain the $20 \%$ atmospheric $\mathrm{O}_{2}$ environment.

Cell viability/death andROS staining. Ethidium homodimer-1 (EthD) and calcein AM (Viability/Cytotoxicity assay kits; Biotium Inc., Hayward, CA, USA) mixtures were used to stain the cultured hLECs and used in accordance with the manufacturer's recommendations. 2',7'-Dichlorodihydrofluorescein diacetate (H2-DCFH-DA; Invitrogen Life Technologies, Grand island, NY, USA) in phosphate-buffered saline (PBS) at a concentration of $1 \mathrm{mg} / \mathrm{ml}$ was used to determine the cytosolic ROS level. The mixture was allowed to stand for $40 \mathrm{~min}$ at $20^{\circ} \mathrm{C}$, then washed with PBS twice and subjected to microscopic imaging using a fluorescence microscope (Nikon TE2000-U; Nikon Corporation, Tokyo, Japan).

Evaluation of protein levels in hLECs. Protein levels were determined by western blotting. RIPA buffer (Cell Signaling Technology, Danvers, MA, USA) was used to lyse the cultured hLECs and the proteins were separated by SDS-PAGE. The gels were then blotted onto nitrocellulose membranes, which were blocked in PBS buffer $(\mathrm{pH} \mathrm{8.0)}$ containing $5 \%$ non-fat milk for $1 \mathrm{~h}$. The primary antibodies were to the following proteins: Binding immunoglobulin protein (BiP; cat. no. sc-33757; rabbit polyclonal IgG, 1:500; Santa Cruz Biotechnology Inc., Dallas, TX, USA), ATF4 (cat. no. ab23760; rabbit polyclonal IgG, 1:500; Abcam, Cambridge, MA, USA), ATF6 (cat. no. ab37149; rabbit polyclonal IgG, 1:500; Abcam), CHOP (cat. no. MA1-250; mouse monoclonal IgG, 1:500; Invitrogen Life Technologies, Carlsbad, CA, USA), ER oxidoreductin 1-like (Ero1-L) $\alpha$ (cat. no. sc-100805; mouse polyclonal IgG, 1:500; Santa Cruz Biotechnology, Inc.), Ero1-L $\beta$ (cat. no. sc-162776; goat polyclonal IgG, 1:500; Santa Cruz Biotechnology, Inc.), hypoxia-inducible factor (HIF)-1 $\alpha$ (cat. no. ab16066; mouse monoclonal IgG, 1:500; Santa Cruz Biotechnology, Inc.), kelchlike ECH-associated protein 1 (Keap1; cat. no. sc-15246; goat polyclonal IgG, 1:500; Santa Cruz Biotechnology, Inc.), Nrf2 (cat. no. sc-722; rabbit polyclonal IgG, 1:500; Santa Cruz Biotechnology, Inc.), protein disulfide isomerase (PDI; cat. no. sc-20132; rabbit polyclonal IgG, 1:500; Santa Cruz Biotechnology, Inc.), phospho (p)-eIF2 $\alpha$ (cat. no. sc-101670; rabbit polyclonal Ig G, 1:500; Santa Cruz Biotechnology, Inc.), p-IRE1 $\alpha$ (cat. no. PA1-16927; rabbit polyclonal IgG, 1:500; Invitrogen Life Technologies), p-PERK (cat. no. sc-32577; rabbit polyclonal IgG, 1:500; Santa Cruz Biotechnology, Inc.) and GAPDH (cat. no. sc-25778; rabbit polyclonal IgG, 1:500; Santa Cruz Biotechnology Inc.). Anti-caspase-4 antibodies (cat. no. sc-56056; mouse monoclonal IgG; 1:500; Santa Cruz Biotechnology Inc.) were used in western blot analysis. The membranes were incubated with primary antibody at $4{ }^{\circ} \mathrm{C}$ overnight and then with the secondary antibodies (cat. no. sc-56056; goat anti-rabbit IgG-horseradish peroxidase goat polyclonal, 1:5000; Santa Cruz Biotechnology Inc.) for $1 \mathrm{~h}$ at room temperature. The intensity of each band was normalized to that of GAPDH, and the data are presented as relative intensities, which were determined using ImageJ analysis software (National Institutes of Health, Bethesda, MD, USA).

Evaluation of mRNA levels in hLECs. Total RNA was extracted from the hLECs exposed to various $\mathrm{O}_{2}$ environments using TRIzol reagent (Invitrogen Life Technologies) according to the manufacturer's instructions. The purified total RNA was reverse transcribed using iScript ${ }^{\mathrm{TM}}$ Reverse Transcription Supermix for real-time PCR (Bio-Rad T100; Bio-Rad, Hercules, CA, USA) following the manufacturer's instructions. The reverse transcribed RNA was analyzed by quantitative polymerase chain reaction using SsoFast ${ }^{\mathrm{TM}}$ EvaGreen ${ }^{\circledR}$ Supermix (Bio-Rad). The primer sequences for Nrf2, Keap1, and $\beta$-actin as described by Elanchezhian et al (5) were used for mRNA detection. The primer sequences for Nrf2, Keap1, and $\beta$-actin were: Nrf2 sense, 5'-ACACGGTCCACAGCTCATC-3' and antisense, 5'-TGCCTCCAAAGTATGTCAATCA-3': Keap1 sense, 5'-GGGTCCCCTACAGCCAAG-3' and antisense, 5'-TGGGGTTCCAGAAGATAAGC-3'; and $\beta$-actin sense 5'-CCAACCGCGAGAAGATGA-3' and 5'-CCAGAGGCGTACAGGGATAG-3' antisense. Each reaction was carried out in triplicate and three independent experiments were run. A standard curve was prepared, relative copy numbers were obtained from the standard curve and the relative expression levels were normalized to the values obtained for $\beta$-actin.

Statistical analysis. Results are presented as the mean \pm standard deviation from three individual experiments. P-values were determined by Student's t-tests and analyzed using SPSS software, (version 16.0; SPSS Inc., Chicago, IL, USA). 
A

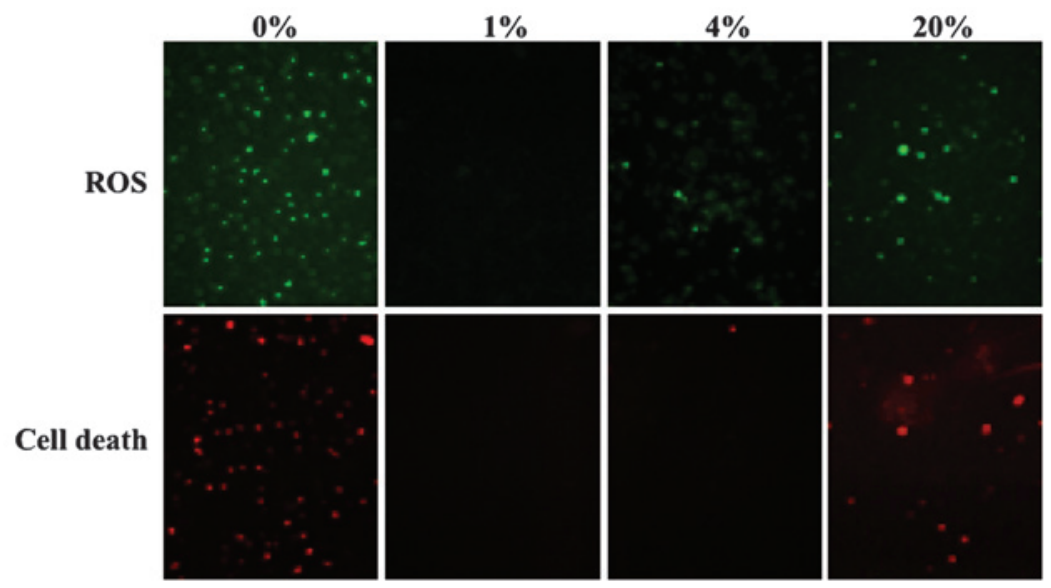

B

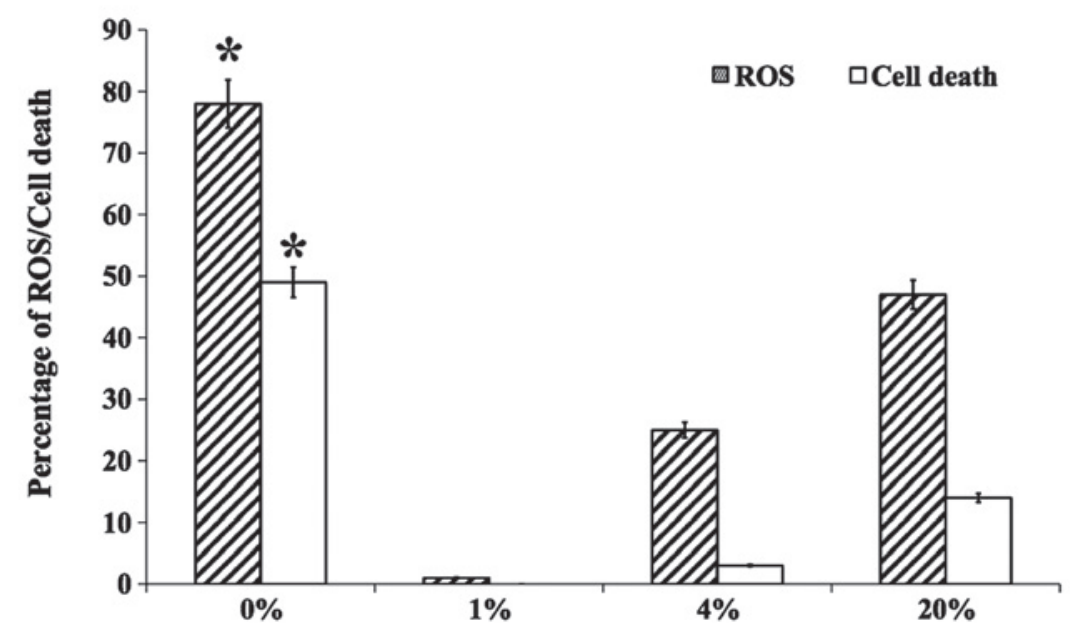

Figure 1. (A) Fluorescent staining of ROS and cell death in hLECs cultured for $24 \mathrm{~h}$ with $0,1,4$ and $20 \%$ oxygen (magnification, $\mathrm{x} 100$ ). (B) Graphical representation of percentage of ROS and cell death obtained by quantifying the staining intensity of the cells. ${ }^{*} \mathrm{P}<0.05$ vs. $20 \%$ oxygen. ROS, reactive oxygen species; hLECs, human lens epithelial cells.
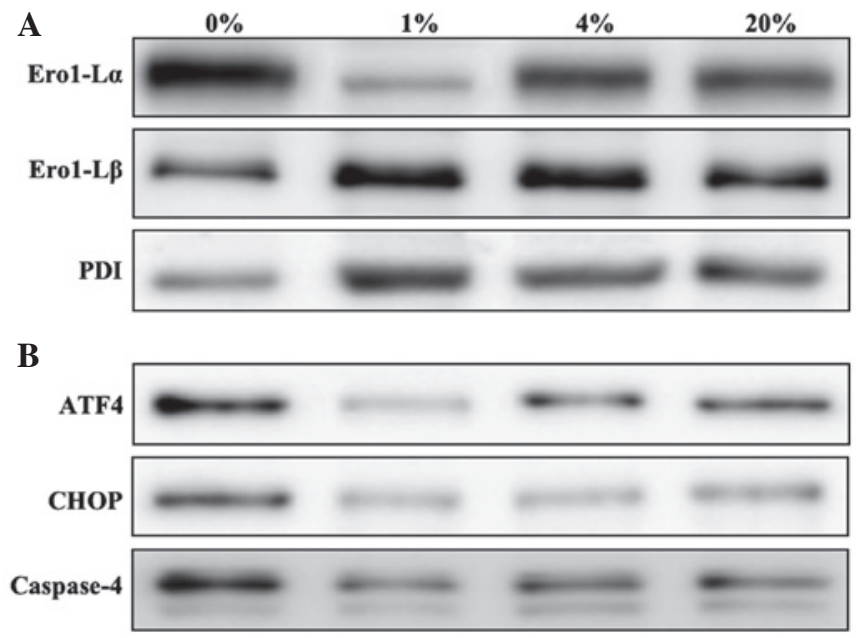

Figure 2. Western blot analysis of ROS- and apoptosis-related UPR proteins. (A) ROS-related and (B) apoptosis-related UPR proteins in the hLECs cultured for $24 \mathrm{~h}$ with $0,1,4$ and $20 \%$ oxygen. ROS, reactive oxygen species; UPR, unfolded protein response; Erol-L, endoplasmic reticulum oxidoreductin 1-like; PDI, protein disulfide isomerase; ATF4, activating transcription factor 4; CHOP, C/EBP homologous protein.

$\mathrm{P}<0.05$ was considered to indicate a statistically significant result.

\section{Results}

ROS production and cell death. hLECs that were cultured in different levels of $\mathrm{O}_{2}$ were stained for the evaluation of ROS production and cell death (Fig. 1A). The production of ROS was found to be significantly increased in 0 and $20 \% \mathrm{O}_{2}$ than in 1 and $4 \% \mathrm{O}_{2}$ (Fig. 1B). A similar pattern was observed for dead cell staining, with no cell death observed in 1 and $4 \% \mathrm{O}_{2}$ (Fig. 1). The levels of ROS- (Fig. 2A) and apoptosis-related ER stress proteins (Fig. 2B) were then investigated. The ROS-related ER stress proteins that were investigated were Erol-L $\alpha$, Ero1-L $\beta$ and PDI. An increased level of Erol-L $\alpha$ was detected in cells cultured with 0, 4 and $20 \% \mathrm{O}_{2}$. However, Ero1-L $\beta$ and PDI were detected at greater levels in hLECs cultured in $1 \% \mathrm{O}_{2}$ than in those cultured in other percentages of $\mathrm{O}_{2}$ (Fig. 2A). The apoptosis-related ER stress proteins that were investigated were ATF4, CHOP and caspase-4. Similar to the ROS-related protein Ero1-L $\alpha$, apoptotic proteins were detected in greater quantities in hLECs cultured in $0 \% \mathrm{O}_{2}$ than in those cultured in other percentages of $\mathrm{O}_{2}$ (Fig. 2B). Notably, cells cultured in $1 \%$ $\mathrm{O}_{2}$ revealed a protective effect when compared with the cells cultured in other percentages of $\mathrm{O}_{2}$.

Detection of $\mathrm{O}_{2}$ deprivation with different percentages of $\mathrm{O}_{2}$. hLECs were cultured in $0,1,4$ and $20 \% \mathrm{O}_{2}$ and cells were 


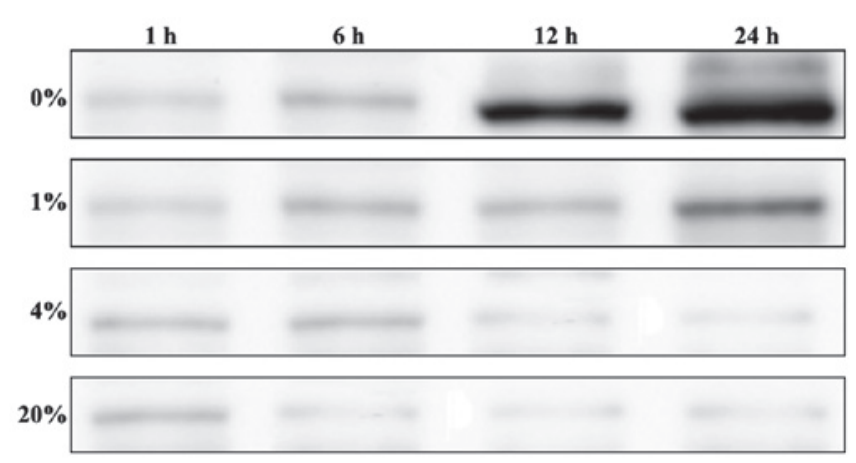

Figure 3. Western blot analysis of the protein levels of HIF)-1 $\alpha$ hypoxia-inducible factor in hLECs cultured for $1,6,12$ and $24 \mathrm{~h}$ with $0,1,4$ and $20 \%$ oxygen. HIF, hypoxia-inducible factor; hLECs, human lens epithelial cells.

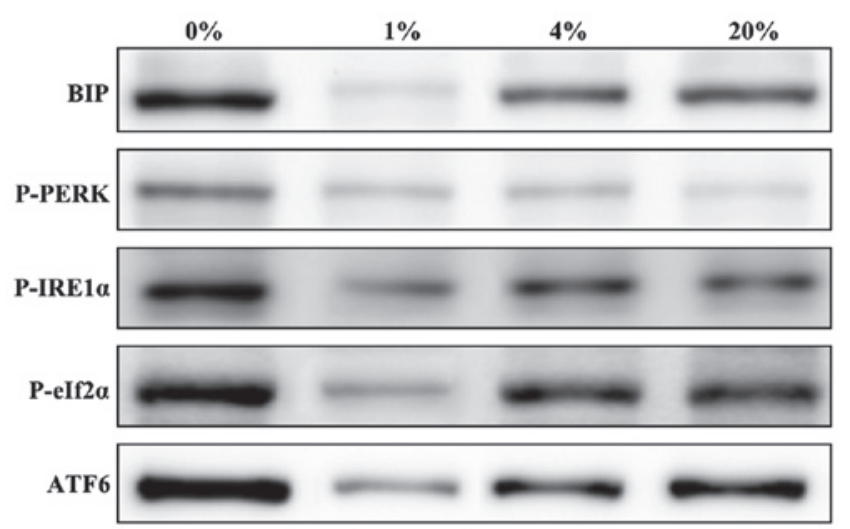

Figure 4. Representative western blots of ER stress-related UPR proteins in hLECs cultured for $24 \mathrm{~h}$ with $0,1,4$ and $20 \%$ oxygen. ER, endoplasmic reticulum; UPR, unfolded protein response; $\mathrm{BiP}$, binding immunoglobulin protein; p, phospho; PERK, PKR-like endoplasmic reticulum kinase; IRE1 $\alpha$, inositol-requiring enzyme $1 \alpha$; elf $2 \alpha$, eukaryotic translation initiation factor $2 \alpha$; ATF6, activating transcription factor 6 .

collected at various time intervals $(1,6,12$ and $24 \mathrm{~h})$ for the investigation of HIF-1 $\alpha$ levels. Increased levels of HIF-1 $\alpha$ were detected in the cells cultured in $0 \% \mathrm{O}_{2}$ from $6 \mathrm{~h}$, and the HIF-1 $\alpha$ levels were significantly increased following $24 \mathrm{~h}$ of culture (Fig. 3). However, the cells cultured in $1 \% \mathrm{O}_{2}$ showed minimum levels of HIF-1 $\alpha$ when compared with those cultured in $0 \% \mathrm{O}_{2}$. The other $\mathrm{O}_{2}$ percentages, 4 and 20\%, showed a minimal HIF- $1 \alpha$ protein levels (Fig. 3).

Evaluation of ER stress proteins. To elucidate the hypothesis concerning the induction of ER stress by $\mathrm{O}_{2}$ fluctuation, the levels of ER stress proteins in cells cultured for $24 \mathrm{~h}$ with 0,1 , 4 and $20 \% \mathrm{O}_{2}$ were investigated. The ER stress marker protein $\mathrm{BiP}$ and the UPR-associated proteins p-PERK, p-IRE1 $\alpha$, p-eIF2 $\alpha$ and ATF6 were investigated. Increased levels of ER stress proteins were found in cells cultured with 0 and $20 \% \mathrm{O}_{2}$ when compared with those cultured with 1 and $4 \% \mathrm{O}_{2}$ (Fig. 4). However, very minimal or negligible amounts of ER stress proteins were detected in cells cultured in $1 \% \mathrm{O}_{2}$, which clearly indicates that this is a protective environment for the growth of hLECs.

Evaluation of key antioxidant proteins. The effect of different percentages of $\mathrm{O}_{2}$ on the levels of the lens antioxidant proteins
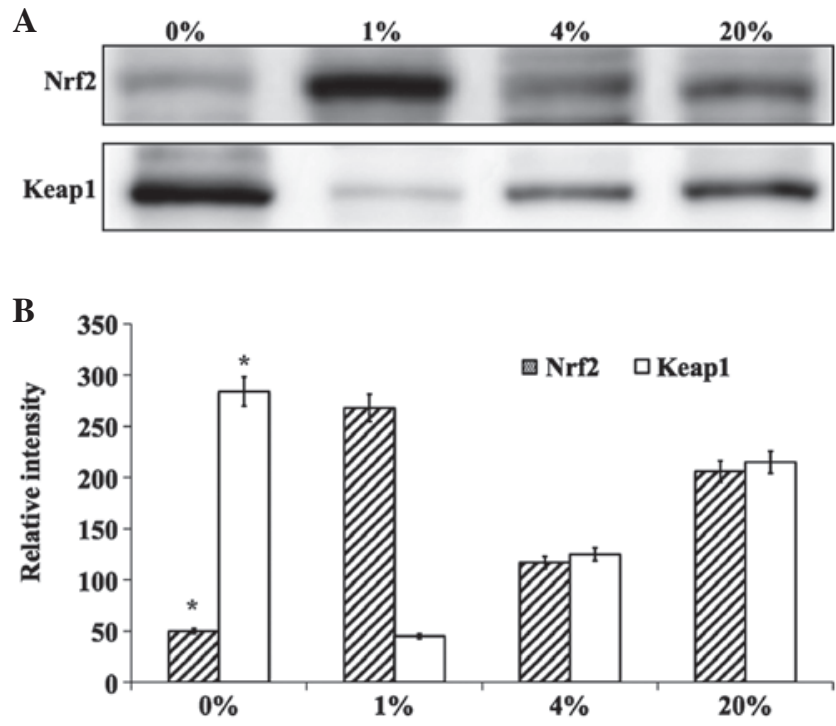

Figure 5. (A) Representative western blot analysis of antioxidant proteins in hLECs cultured for $24 \mathrm{~h}$ with $0,1,4$ and $20 \%$ oxygen. (B) Graphical representation of relative intensity of corresponding antioxidant blots quantified by image analysis. ${ }^{*} \mathrm{P}<0.05$ vs. $20 \%$ oxygen. hLECs, human lens epithelial cells; Nrf2, NF-E2-related factor 2; Keap1, kelch-like ECH-associated protein 1.

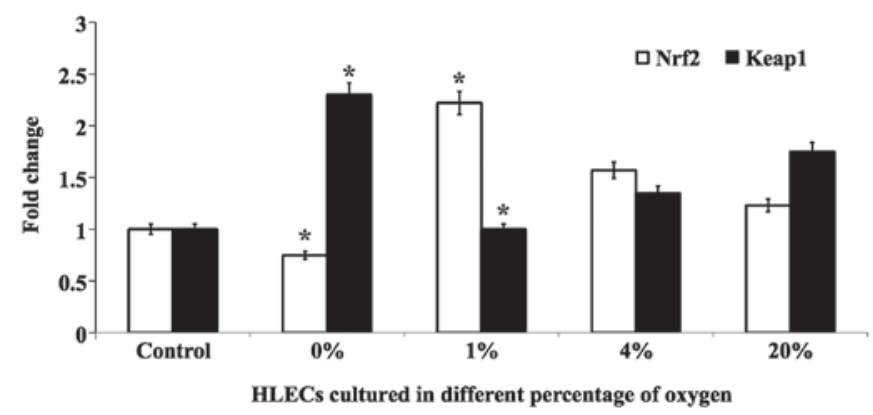

Figure 6. Graphical representation of mRNA quantification of antioxidants Nrf2 and Keap1 in hLECs cultured for $24 \mathrm{~h}$ with 0, 1, 4 and $20 \%$ oxygen. " $\mathrm{P}<0.05$ vs. $20 \%$ oxygen. hLECs, human lens epithelial cells; Nrf2, NF-E2-related factor 2; Keap1, kelch-like ECH-associated protein 1.

Nrf2 and Keap1 were investigated. The effects were evaluated in cells cultured for $24 \mathrm{~h}$ in $0,1,4$ and $20 \% \mathrm{O}_{2}$ by quantifying Nrf2 and Keap1 at the protein and mRNA levels. Notably, cells cultured in $1 \% \mathrm{O}_{2}$ showed a protective effect and the level of Nrf2 protein was increased to near normal levels (Fig. 5). However, cells cultured in 0,4 and $20 \% \mathrm{O}_{2}$ showed decreased levels of this protein. The inverse effect was observed for Keap1 protein (Fig. 5). The mRNA levels of Nrf2 and Keap1 followed similar trends (Fig. 6). Altogether, it is clear that $1 \% \mathrm{O}_{2}$ was found to be protective for cultured hLECs when compared with other percentages of $\mathrm{O}_{2}$. In addition, a complete lack of $\mathrm{O}_{2}(0 \%)$ resulted in severe damage to lens proteins due to the induction of ER stress, where chronic exposure led to the production of ROS and cell death.

\section{Discussion}

Lens researchers generally consider that age-related cataracts (ARCs) are strongly associated with lens oxidation and aging (16-18). Although a direct association between cataract 
formation and hypoxia has not been clearly demonstrated, there are many adverse conditions that lead to hypoxic disorders in the human lens. In the present study, exposure of hLECs to certain $\mathrm{O}_{2}$ environments was found to activate a protective UPR, whereas prolonged exposure to severe hypoxia induced ROS production and apoptotic UPR. This response was observed as LEC death and lens oxidation. The obtained results are in line with previous studies, in which cataracts under diabetic conditions have been found to be strongly associated with agedependent circulatory disorders and also dependent on diastolic blood pressure, the duration of diabetes, elevated glycosylated hemoglobin levels and lower intraocular pressure $(19,20)$.

In addition, metabolic diseases and extreme fasting conditions have been found to induce hypoglycemia; a recent study showed that a 30-min exposure to very low glucose was adequate to induce an UPR in the germinative zone of the lens in rodents (5) and hyperoxia and hyperglycemia are been widely reported to induce oxidation in the lens and cataract formation $(21,22)$. The present study has revealed that physiological concentrations of $\mathrm{O}_{2}$ concentrations also induce lens oxidation and activate the UPR, indicating that hypoxia and hyperoxia are potentially contributing factors to oxidation in lenses.

Kiviluoto et al (23) reported that the activation of ER stress proteins deplete the level of $\mathrm{Ca}^{2+}$ in the ER-; the ER-Ca ${ }^{2+}$ level along with ER localized oxidative machinery is vital for appropriate protein folding. The results of the present study suggest that the culture of hLECs under severe hypoxia $\left(0 \% \mathrm{O}_{2}\right)$ or hyperoxia $\left(20 \% \mathrm{O}_{2}\right)$ induces apoptotic UPR leading to ROS production; this may also lead to the release of $\mathrm{Ca}^{2+}$ from the ER, consequently increasing cytosolic $\mathrm{Ca}^{2+}$ and thus inducing apoptosis and causing severe impairment in the hLECs. It may be hypothesized that aged individuals develop cortical or nuclear cataracts due to the induction of UPR and also due to ROS production in LECs.

A study by Elanchezhian et al (5) demonstrated that ROS increased in LECs in the germinative zone that differentiate into cortical fiber cells, where new fiber cells are generated over old lens fiber cells. These lens fiber cells were suggested to contain less Nrf2-dependent antioxidant protection, and the changes result in crystallin aggregation and oxidation in the posterior and cortical regions. Moreover, earlier findings have reported that diabetic cataracts are intensely associated with diabetic exposure time $(19,20)$, where longer exposure results in an increased density of the cortical lens fiber cell layer.

Thus, the present study has revealed that $1 \% \mathrm{O}_{2}$ is a protective environment for the healthy growth of hLECs. However, 0 and $20 \% \mathrm{O}_{2}$ may activate the UPR, and prolonged exposure leads to the production of ROS, oxidation of the lens and ultimately leads to cell death. Maintaining cells in $1 \% \mathrm{O}_{2}$ can attenuate $\mathrm{O}_{2}$-fluctuation induced ER stress. The results of this study suggest that $1 \% \mathrm{O}_{2}$ provides a protective environment for the healthy cell culture and experimental use of hLECs.

\section{Acknowledgements}

The present study was supported by grants from the National Science Foundation of China (no. 81202021), the National Science Foundation of Zhejiang Province, China (no. LQ13H120001) and the Key Laboratory of Diagnosis and Treatment of Neonatal Diseases of Zhejiang Province.

\section{References}

1. Tabin G, Chen M and Espandar L. Cataract surgery for the developing world. Curr Opin Ophthalmol 19: 55-59, 2008.

2. Barbazetto IA, Liang J, Chang S, Zheng L, Spector A and Dillon JP: Oxygen tension in the rabbit lens and vitreous before and after vitrectomy. Exp Eye Res 78: 917-924, 2004.

3. McNulty R, Wang H, Mathias RT, Ortwerth BJ, Truscott RJ and Bassnett S: Regulation of tissue oxygen levels in the mammalian lens. J Physiol 559: 883-898, 2004.

4. Shui YB, Fu JJ, Garcia C, Dattilo LK, Rajagopal R, McMillan S, Mak G, Holekamp NM, Lewis A and Beebe DC. Oxygen distribution in the rabbit eye and oxygen consumption by the lens. Invest Ophthalmol Vis Sci 47: 1571-1580, 2006.

5. Elanchezhian R, Palsamy P, Madson CJ, Mulhern ML, Lynch DW, Troia AM, Usukura J and Shinohara T: Low glucose under hypoxic conditions induces unfolded protein response and produces reactive oxygen species in lens epithelial cells. Cell Death Dis 3: e301, 2012.

6. Ikesugi K, Yamamoto R, Mulhern ML and Shinohara T. Role of the unfolded protein response (UPR) in cataract formation. Exp Eye Res 83: 508-516, 2006.

7. Elanchezhian R, Palsamy P, Madson CJ, Lynch DW and Shinohara T. Age-related cataracts: Homocysteine coupled endoplasmic reticulum stress and suppression of Nrf2-dependent antioxidant protection. Chem Biol Interact 200: 1-10, 2012.

8. Helbig H, Hinz JP, Kellner U and Foerster MH. Oxygen in the anterior chamber of the human eye. Ger J Ophthalmol 2: 161-164, 1993.

9. Bassnett $\mathrm{S}$ and McNulty R. The effect of elevated intraocular oxygen on organelle degradation in the embryonic chicken lens. J Exp Biol 206: 4353-4361, 2003.

10. Mulhern ML, Madson CJ, Danford A, Ikesugi K, Kador PF and Shinohara T. The unfolded protein response in lens epithelial cells from galactosemic rat lenses. Invest Ophthalmol Vis Sci 47: 39513959, 2006.

11. Xie Q, Khaoustov VI, Chung CC, Sohn J, Krishnan B, Lewis DE and Yoffe B: Effect of tauroursodeoxycholic acid on endoplasmic reticulum stress-induced caspase-12 activation. Hepatology 36 : 592-601, 2002.

12. Tinhofer I, Anether G, Senfter M, Pfaller K, Bernhard D, Hara M and Greil R: Stressful death of T-ALL tumor cells after treatment with the anti-tumor agent Tetrocarcin-A. FASEB J 16: 1295-1297, 2002.

13. Hettmann T, Barton K and Leiden JM: Microphthalmia due to p53-mediated apoptosis of anterior lens epithelial cells in mice lacking the CREB-2 transcription factor. Dev Biol 222: 110-123, 2000.

14. Tu BP and Weissman JS: The FAD- and $\mathrm{O}_{2}$-dependent reaction cycle of Ero1-mediated oxidative protein folding in the endoplasmic reticulum. Mol Cell 10: 983-994, 2002.

15. Pagani M, Fabbri M, Benedetti C, Fassio A, Pilati S, Bulleid NJ, Cabibbo A and Sitia R: Endoplasmic reticulum oxidoreductin 1-Lbeta (ERO1-Lbeta), a human gene induced in the course of the unfolded protein response. J Biol Chem 275: 23685-23692, 2000.

16. Baynes JW and Thorpe SR. Role of oxidative stress in diabetic complications: A new perspective on an old paradigm. Diabetes 48: 1-9, 1999.

17. Brennan LA and Kantorow M. Mitochondrial function and redox control in the aging eye: Role of MsrA and other repair systems in cataract and macular degenerations. Exp Eye Res 88: 195-203, 2009.

18. Lou MF. Redox regulation in the lens. Prog Retin Eye Res 22: 657-682, 2003.

19. Harding JJ: Recent studies of risk factors and protective factors for cataract. Curr Opin Ophthalmol 8: 46-49, 1997.

20. Negahban K and Chern K: Cataracts associated with systemic disorders and syndromes. Curr Opin Ophthalmol 13: 419-422, 2002.

21. Simpanya MF, Ansari RR, Suh KI, Leverenz VR and Giblin FJ: Aggregation of lens crystallins in an in vivo hyperbaric oxygen guinea pig model of nuclear cataract: Dynamic light-scattering and HPLC analysis. Invest Ophthalmol Vis Sci 46: 4641-4651, 2005.

22. Simpanya MF, Ansari RR, Leverenz V and Giblin FJ: Measurement of lens protein aggregation in vivo using dynamic light scattering in a guinea pig/UVA model for nuclear cataract. Photochem Photobiol 84: 1589-1595, 2008.

23. Kiviluoto S, Vervliet T, Ivanova H, Decuypere JP, De Smedt H, Missiaen L, Bultynck G and Parys JB. Regulation of inositol 1,4,5-trisphosphate receptors during endoplasmic reticulum stress. Biochim Biophys Acta 1833: 1612-1624, 2013. 